\title{
MEDIA EDUKASI PEMBELAJARAN 3D HEWAN DAN BUAH MENGGUNAKAN AUGMENTED REALITY BERBASIS ANDROID
}

\section{VIKY ADITYA PRATAMA}

Teknik Informatika, Fakultas Teknik

Universitas Maarif Hasyim Latif, Sidoarjo, Indonesia

e-mail : adietyacviqqy06@gmail.com

\section{ABSTRAK}

Sebagian orang merasa kesulitan untuk menarik minat anak mereka untuk mengenalankan hewan dan buah. Untuk menghilangkan rasa jenuh dalam proses pembelajaran ada satu cara yakni dengan pendekatan melalui game edukasi yang bias diakses melalui handphone, Tujuan pada penelitian ini untuk merancang dan membuat aplikasi edukasi pengenalan hewan dan buah disertai dengan objek 3D. Pembuatan apliaksi ini menggunakan metode penampilan onjek 3D dengan pendeteksian marker. Aplikasi ini dapat membantu memudahkan orang tua dalam memberikan pembelajaran tentang hewan dan buah terhadap anak mereka dengan menggunakan andriod, sehingga dapat menarik minat anak dengan adanya objek 3D dan lebih mudah dalam mengaksesnya karena sudah berbasis android.

Kata kunci: ar, augmented reality, hewan, buah

\section{PENDAHULUAN}

Banyak metode yang dapat diterapkan agar anak usia dini dapat lebih mengenal lingkungannya, khususnya mengenal jenis-jenis hewan dan buah, mulai dari mendatangi kebun binatang, taman-taman buah dan menggunakan software buah dan binatang 3D melalui smartphone andoid.

Metode augmented reality menggunakan penggabungan antara benda-benda nyata sebagai marker dan maya sebagai media 3D sehingga memungkinkan tampilan interaktif untuk anakanak dalam hal ini berupa pengenalan hewan dan buah.

Implementasi teknologi ini tidak mengharuskan peralatan dengan biaya mahal untuk dapat menjalankan augmented reality hanya diperlukan dukungan minimal sebuah komputer dan kamera handphone.

\section{METODE PENELITIAN}

\section{Flowchart}

Alur kerja aplikasi augmented reality yang akan dibuat ditunjukan dalam Gambar 1. Pada gambar 1, setelah user memulai aplikasi maka akan otomatis mengaktifkan kamera untuk memulai proses pendeteksian marker. Ketika user salah menyusun marker maka aplikasi menampilkan sebagai salah, dan benar jika user berhasil menyusun dengan benar marker.

\section{Augmented Reality}

Augmented reality dapat menyediakan berbagai informasi yang penting dan pengguna dapat menggunakan seluruh indranya dalam menggunakan AR, sehingga para pengguna dapat lebih mudah dalam pembelajaran dan pelatihan.[1]

Kamera yang sudah dikalibrasi akan bisa mendeteksi marker, melakukan pencocokan apakah marker sama dengan yang di database yang ada bila sama informasi marker akan dipakai untuk menampilkan gambar 3D.

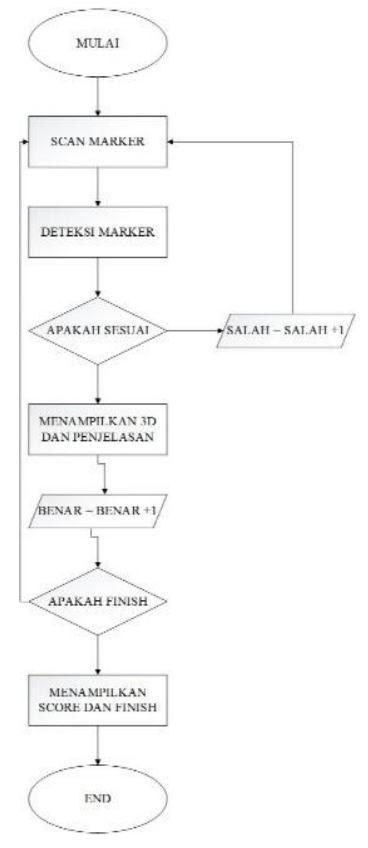

Gambar 1. Flowchart sistem 
Vuforia

Vuforia menganalisa gambar dengan menggunakan pendeteksi marker dan menghasilkan informasi 3D dari marker yang sudah dideteksi via API.[2]

\section{Unity}

Unity bisa untuk games PC dan games Online. Untuk games Online diperlukan sebuah plugin, yaitu Unity Web Player, sama halnya dengan Flash Player pada Browser.[3]

\section{Use Case Diagram}

Diagram use case aplikasi ditunjukan pada Gambar 2.

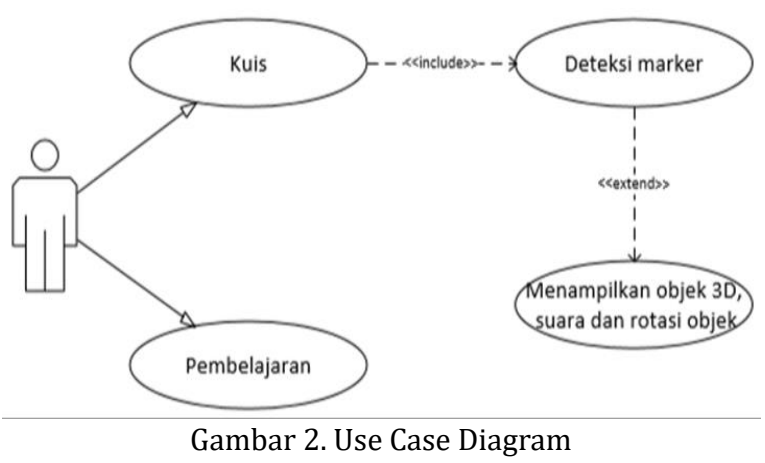

Aktor merupakan pihak yang terlibat didalam sistem. Tujuan dari pembuatan use case salah satunya mendefinisikan kebutuhan fungsional beserta operasional sistem.

\section{Activity Diagram}

Activity diagram dari aplikasi media aplikasi pengenalan hewan dan buah yang akan dibangun terdiri dari activity diagram menu kuis dan activity diagram menu pembelajaran.

\section{a. Activity Diagram Menu Kuis}

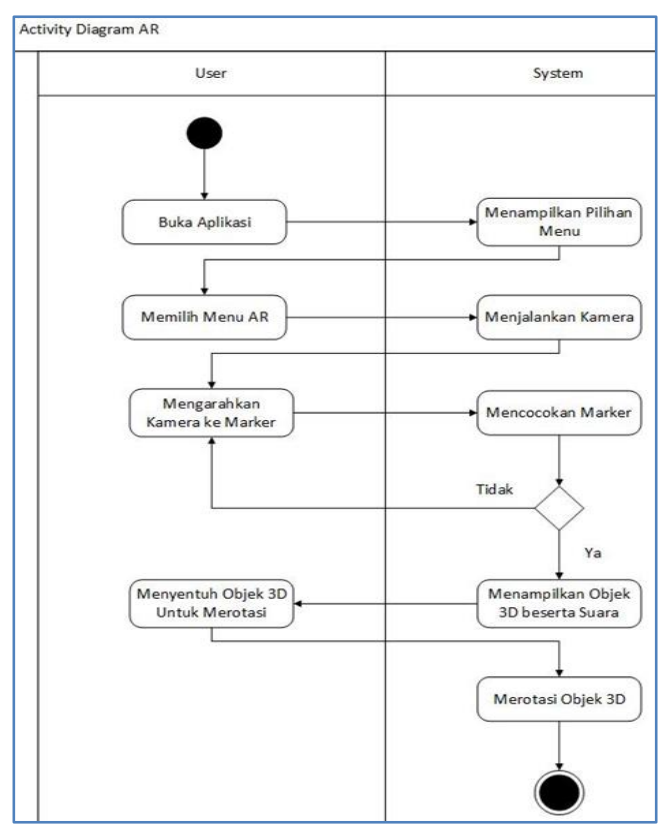

Gambar 3. Activity Diagram Menu Kuis
Aplikasi augmented reality maka akan secara otomatis menjalankan kamera untuk melakukan pencocoan marker, jika marker tersusun secara benar sistem akan tampil objek 3D beserta suara, jika salah akan tampil tanda salah.

\section{b. Activity Diagram Menu Pembelajaran}

Pada menu pembelajaran user dapat memilih akan memilih pembelajaran hewan atau buah. Kemudian sistem akan secara otomatis menampilkan penjelasan tentang menu pembelajaran yang dipilih oleh user. Untuk activity diagram menu Pembelajaran ditunjukan Gambar 4.

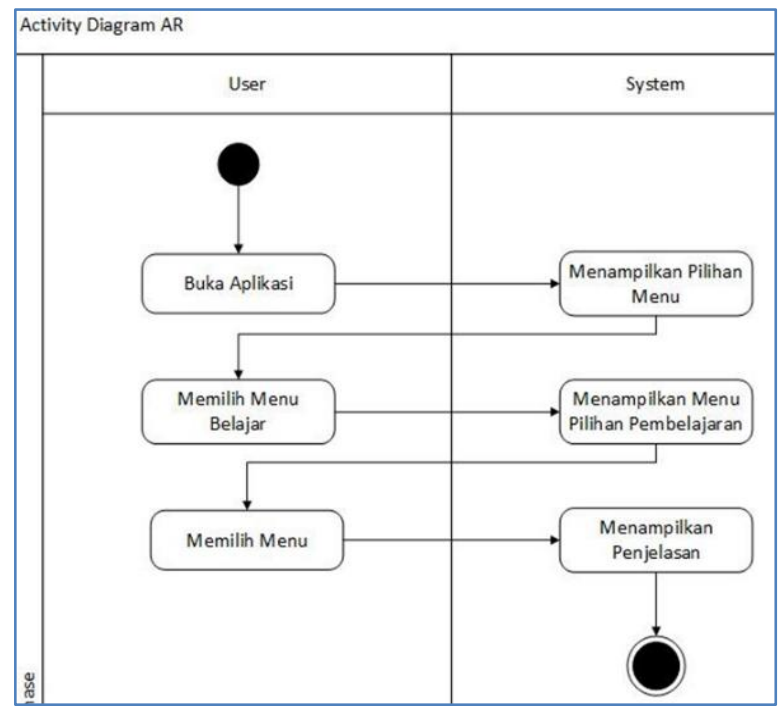

Gambar 4. Activity Diagram Menu Pembelajaran

\section{Blok Diagram Aplikasi}

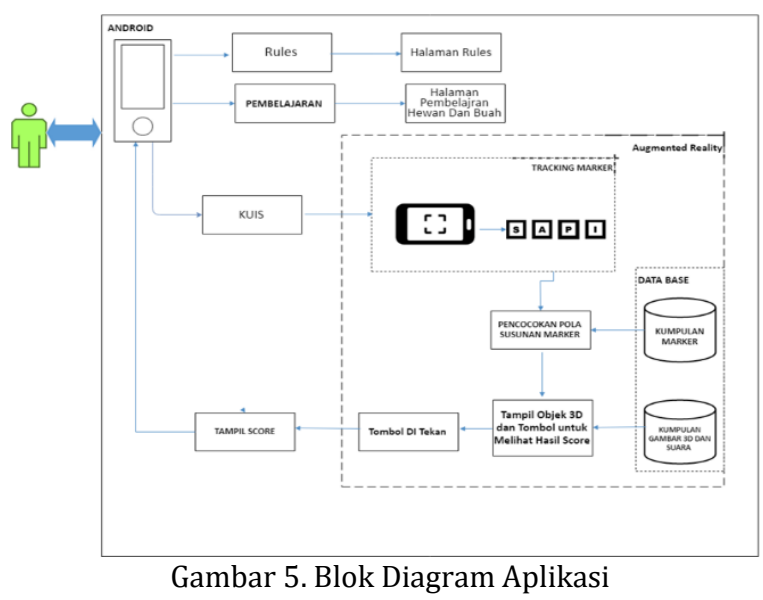

\section{IMPLEMENTASI DAN PEMBAHASAN}

Pada bagian ini akan menjelaskan tentang Implementasi sistem yang menunjukkan hasil dari sesuatu yang telah dikerjakan. Implementasi yang ditunjukkan dapat berupa gambar atau interface dari sistem yang dikerjakan yang menjelaskan minimum spesifikasi komputer yang diperlukan 
untuk menjalankan sistem ini, baik perangkat keras maupun perangkat lunak.

\section{Tampilan Program}

Berikut ini menjelaskan bagaimana sistem ini bekerja dan disertai dengan printscreen setiap tampilan berserta penjelasan dari tiap-tiap menu.

\section{Tampilan Menu Awal}

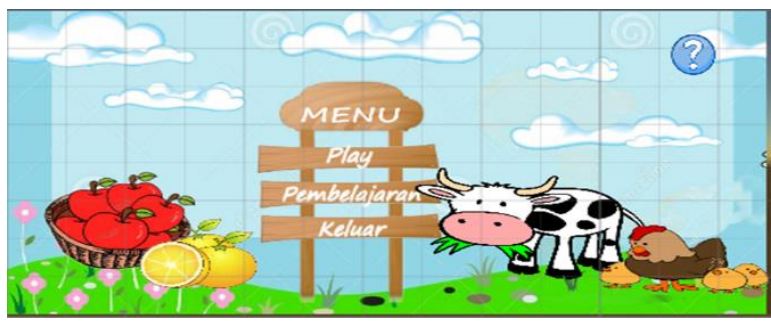

Gambar 6. Tampilan Menu Awal

Tampilan awal muka adalah menu awal dari aplikasi ini. Disini user dapat memilih menu-menu yang terdapat didalam aplikasi.

\section{Halaman Rules}

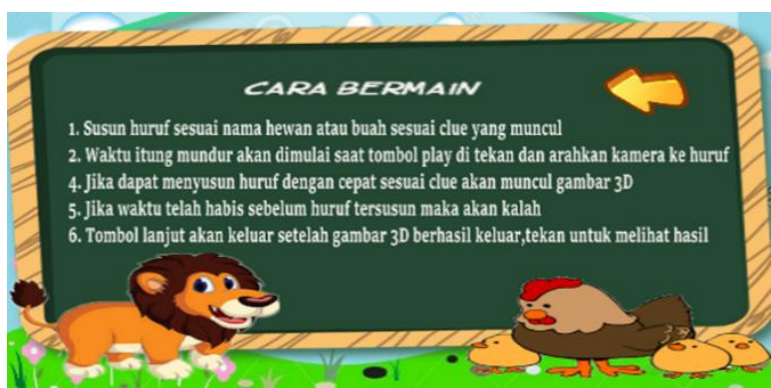

Gambar 7. Halaman Rules

Pada halaman rules ini manampilkan cara atau aturan untuk user dalam memainkan aplikasi ini, dan terdapat tombol kembali untuk user kembali ke menu awal.

\section{Halaman Pembelajaran Hewan}

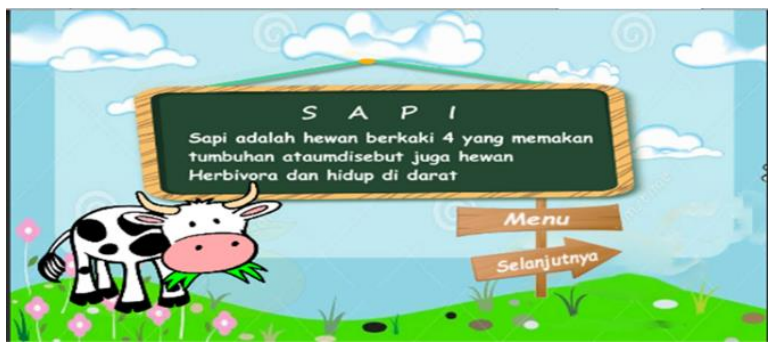

Gambar 8. Halaman Pembelajaran Hewan

Di dalam halaman pembelajaran hewan ini terdapat button menu untuk ke menu awal dan button selanjutnya utnuk ke halaman selanjutnya.

\section{Halaman Pembelajaran Buah}

Pada halaman pembelajaran apel berisi tentang pengejaan huruf beserta penjelasan singkat tentang buah tersebut, di dalam halaman pembelajaran apel ini terdapat button menu ke menu awal dan button selanjutnya utnuk ke halaman selanjutnya.

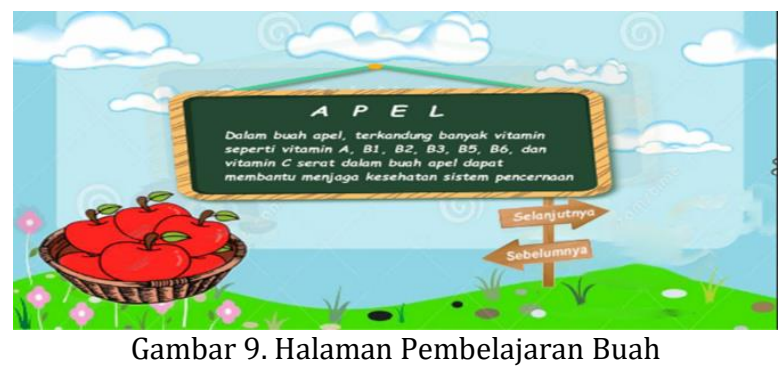

\section{Halaman Hasil Bintang 3}

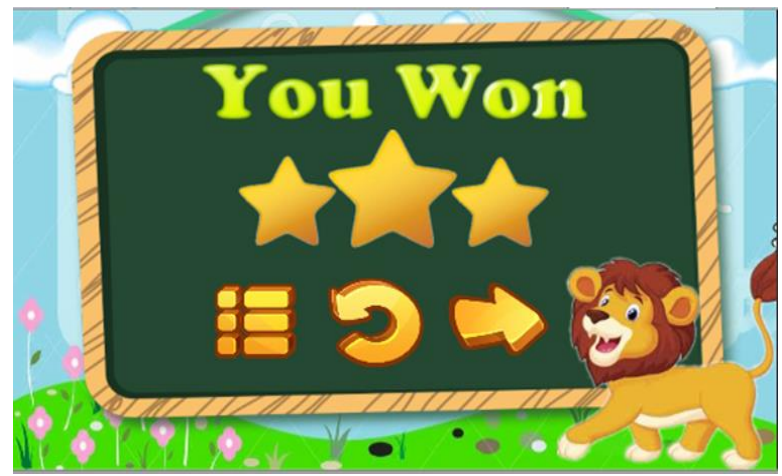

Gambar 10. Halaman Hasil Bintang 3

Tampilan bintang 3 merupakan tampilan yang akan tampil ketika user berhasil menyelesaikan kuis dengan waktu yang cepat, didalam tampilan bintang 3 ini terdapat tiga button navigasi yaitu button menu kembali ke menu utama, button reload untuk mengulang kuis dan button next untuk melanjutkan ke kuis berikutnya.

\section{Halaman Hasil Bintang 2}

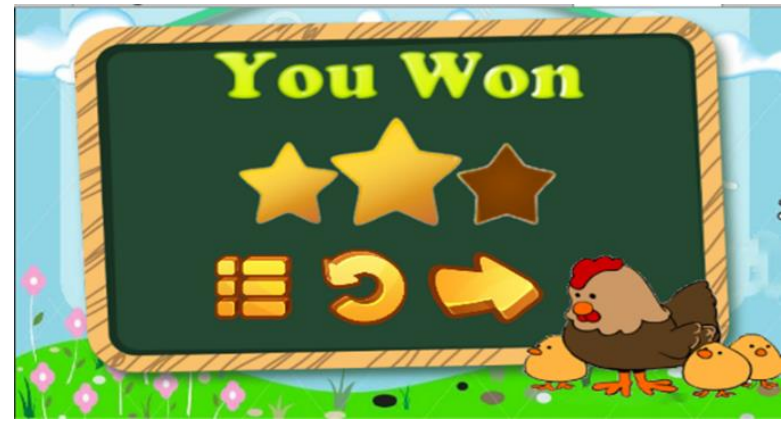

Gambar 11. Halaman Hasil Bintang 2

Tampilan bintang 2 merupakan tampilan yang akan tampil ketika user berhasil menyelesaikan kuis dengan waktu yang cepat, didalam tampilan bintang 2 ini terdapat tiga button navigasi yaitu button menu untuk ke menu utama, button reload untuk mengulang kuis dan button next untuk melanjutkan ke kuis berikutnya.

\section{Halaman Hasil Kalah}


gambar 12 .

Halaman hasil kalah ditunjukan pada

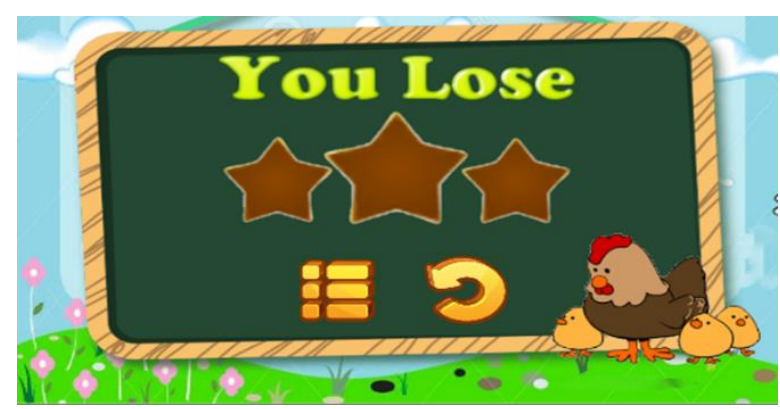

Gambar 12. Halaman Hasil Kalah

Tampilan kalah merupakan tampilan yang akan tampil ketika user tidak berhasil menyelesaikan kuis dengan waktu yang cepat, didalam tampilan hasil kalah ini terdapat dua button navigasi yaitu button menu untuk ke menu utama dan button reload untuk mengulang kuis.

\section{Tampilan Kuis Augmented Reality}

Tampilan kuis unity merupakan rancangan dari halaman kuis yang ada pada aplikasi ini, pada halaman ini dengan menggunakan software unity menggabungkan antara marker dengan gambar 3D.

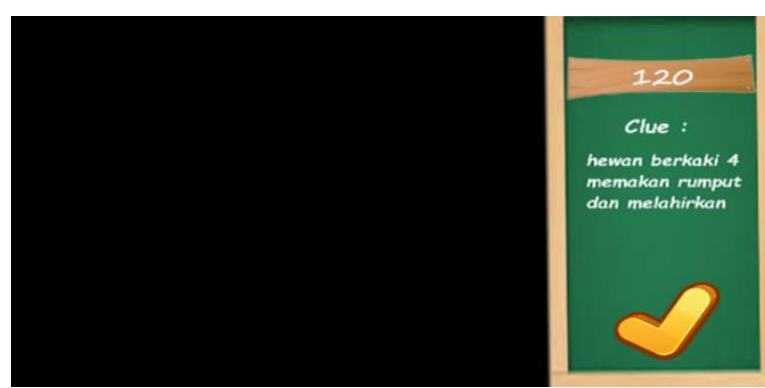

Gambar 13. Tampilan Kuis Augmented Reality

\section{Hasil Uji Skenario}

Pada tabel 1 merupakan hasil uji coba program dari aplikasi media edukasi 3D hewan dan

Tabel 1. Hasil Uji Skenario

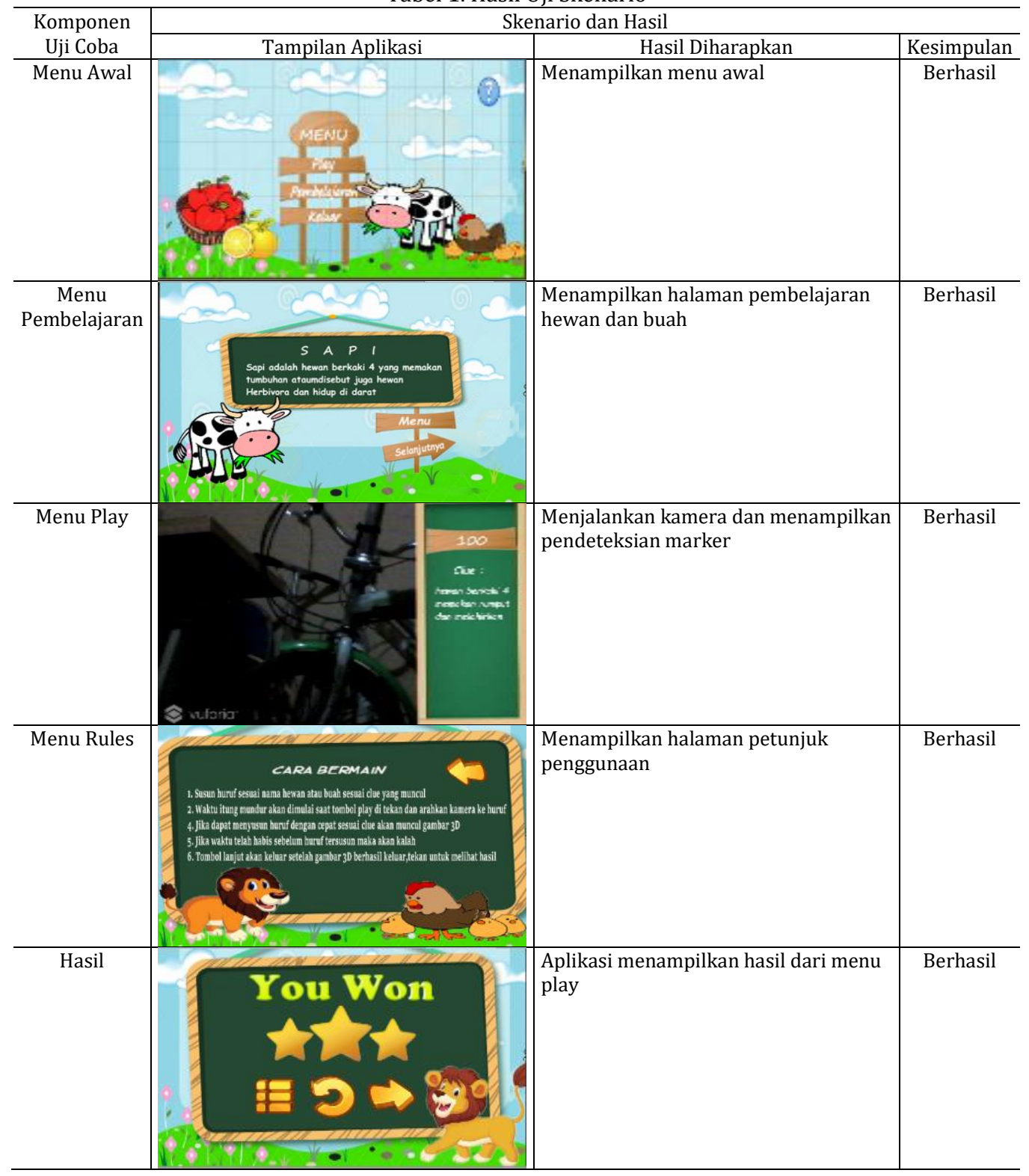


buah.

\section{Pengujian Marker}

Hasil dari pengujian marker ditunjukan pada Tabel 2.

Tabel 2. Pengujian Marker

\begin{tabular}{|c|c|c|l|}
\hline No. & $\begin{array}{c}\text { Jarak } \\
\text { (cm) }\end{array}$ & $\begin{array}{c}\text { Intensitas } \\
\text { Cahaya } \\
\text { (lux) }\end{array}$ & \multicolumn{1}{|c|}{ Kesimpulan } \\
\hline 1. & $0-15$ & 38 & $\begin{array}{l}\text { Terdeteksi, animasi kurang stabil } \\
\text { (terlalu besar) }\end{array}$ \\
\hline 2. & $15-20$ & 39 & $\begin{array}{l}\text { Terdeteksi, animasi stabil (tidak } \\
\text { terlalu besar dan tidak terlalu kecil) }\end{array}$ \\
\hline 3. & $20-30$ & 40 & $\begin{array}{l}\text { Terdeteksi, animasi stabil (tidak } \\
\text { terlalu besar dan tidak terlalu kecil) }\end{array}$ \\
\hline 4. & $30-35$ & 39 & $\begin{array}{l}\text { Terdeteksi, animasi stabil (tidak } \\
\text { terlalu besar dan tidak terlalu kecil) }\end{array}$ \\
\hline 5. & $35-45$ & 40 & $\begin{array}{l}\text { Tidak terdeteksi atau sulit } \\
\text { terdeteksi }\end{array}$ \\
\hline
\end{tabular}

Dari data pengujian pada tabel 2 didapatkan kesimpulan bahwa kemuculan objek 3D pada aplikasi augmented reality sangat pada jarak dan pencahayaan yang meliputi :

a. Semakin besar star ratting marker sehingga jangkauan dari marker pada perangkat semakin jauh.

b. Intensitas cahaya yang baik atau cukup (lux 40) pada saat melakukan pendeteksian marker semakin membuat kemunculan objek 3D tambah besar.

c. Jarak ideal untuk melakukan deteksi marker pada aplikasi augmented reality ini berada pada range antara $20 \mathrm{~cm}$ hingga $35 \mathrm{~cm}$.

d. Jika jarak lebih atau kurang dari pada range tersebut maka kemunculan objek 3D tidak stabil (terlalu besar) atau tidak dapat terdeteksi.

e. Objek 3D yang muncul akan stabil bila marker terlihat seleruhnya atau terdeteksiseluruhnya (tidak terhalang oleh penghalang).

\section{PENUTUP}

Program aplikasi augmented reality ini, adanya program aplikasi augmented reality pembelajaran 3D hewan dan buah ini dapat mempermudah dalam pengenalan nama-nama hewan dan buah beserta manfaatnya. Sehingga dapat mengenalkan kepada anak-anak nama dan penjelasan tentang hewan dan buah yang ada ada aplikasi augmented reality pengenalan hewan dan buah ini.

Perancangan augmented reality pembelajaran hewan dan buah ini dibuat berbasis Android tentunya lebih praktis dan akan lebih menarik minat anak-anak untuk memainkan aplikasi ini di smartphone, sehingga dapat diakses dimanapun dan kapapun, karena aplikasi augmented reality pembelajaran hewan dan buah ini tidak memerlukan koneksi internet untuk menjalankan aplikasi ini sehingga lebih mudah dalam penggunaan.

Pada program aplikasi augmented reality pembelajaran hewan dan buah ini menggunakan gambar 3D dan suara dalam penampilan gambar hewan dan buah, sehingga akan menambah minat anak-anak agar tidak mudah jenuh dalam belajar pengenalan hewan dan buah melalui aplikasi augmented reality ini.

Progam aplikasi augmented reality pembelajaran 3D hewan dan buah berbasis android ini membutuhkan pengembangan lebih lanjut, (1) Objek hewan dan buah yang disajikan masih dalam jumlah yang sedikit, sehingga diharapkan untuk kedepannya agar beragam; (2) aplikasi belum dapat diakses secara online,diharapkan kedepannya aplikasi dapat diakses secara online; (3) aplikasi hanya pada platform android, untuk kedepannya bisa dikembangkan agar bisa digunakan di banyak platform; dan (4) pada aplikasi ini masih menggunakan objek statis untuk 3D, untuk kedepannya diharapkan dapat dikembangkan dalam bentuk animasi agar lebih menarik.

\section{DAFTAR PUSTAKA}

[1] R. Hartono, Liliana, and Yulia, "Pembuatan Aplikasi Augmented Reality Pembelajaran Hewan," J. Infra, vol. 4, no. 2, pp. 121-125, 2016.

[2] Y. Indrawaty, M. Ichwan, and W. Putra, "MEDIA PEMBELAJARAN INTERAKTIF PENGENALAN ANATOMI MANUSIA MENGGUNAKAN METODE AUGMENTED REALITY (AR)," J. Inform., vol. 4, no. 2, pp. 1-8, 2010.

[3] I. B. M. Mahendra, "IMPLEMENTASI AUGMENTED REALITY (AR) MENGGUNAKAN UNITY 3D DAN VUPORIA SDK," JIK J. IImu Komput., vol. 9, no. 1, pp. 1-5, 2016.

[4] Uliontang, E. Setyati, and F. H. Chandra, "PEMANFAATAN AUGMENTED REALITY PADA MEDIA PEMBELAJARAN SEJARAH TENTANG BENDA-BENDA BERSEJARAH PENINGGALAN KERAJAAN MAJAPAHIT DI TROWULAN MOJOKERTO," Tek. Eng. Sains J., vol. 4, no. 1, pp. 19-26, Jun. 2020.

[5] T. T. Zuono et al., "Build design introduction to university profiles using the logo with the augmented reality method," in Journal of Physics: Conference Series, 2019, vol. 1175, no. 1, p. 12115. 
VA Pratama / Ubiquitous: Computers and its Applications Journal, Vol. 3, No. 2, Desember 2020, 87-92 